\title{
SENTIDOS DO ENSINO MÉDIO INTEGRADO: UM ESTUDO DE CASO NO INSTITUTO FEDERAL DO NORTE DE MINAS GERAIS - IFNMG - CAMPUS ALMENARA
}

\author{
MEANINGS OF INTEGRATED HIGH SCHOOL: A CASE STUDY AT FEDERAL \\ INSTITUTE OF NORTHERN MINAS GERAIS - IFNMG - CAMPUS ALMENARA
}

\begin{abstract}
SENTIDOS DE LA ESCUELA SECUNDARIA INTEGRADA: UN ESTUDIO DE CASO
EN INSTITUTO FEDERAL DEL NORTE DE MINAS GERAIS - IFNMG - CAMPUS
\end{abstract}

ALMENARA

Ronivaldo Ferreira Mendes

Instituto Federal de Educação, Ciência e Tecnologia do Norte de Minas Gerais - Brasil

Welisson Marques Instituto Federal de Educação, Ciência e Tecnologia do Triângulo Mineiro - Brasil

\begin{abstract}
Resumo: Esta pesquisa é um recorte da dissertação do programa de mestrado profissional em educação tecnológica do IFTM - Campus Uberaba-MG e, tem como objetivo analisar, por meio dos discursos dos sujeitos-professores atuantes nos cursos técnicos integrados ao ensino médio no IFNMG - Campus Almenara, os sentidos de "integração" e de "curso técnico integrado ao ensino médio". No que tange ao delineamento teórico-metodológico, a pesquisa possui abordagem qualitativa, utiliza-se como instrumento de coleta de dados entrevistas semiestruturadas com o quantitativo de seis sujeitosprofessores participantes da pesquisa que atuam em um dos cursos técnicos integrados ao ensino médio na referida instituição. Fundamentamo-nos nos pressupostos da Análise do Discurso (doravante AD) de linha francesa, à luz da episteme do pensador Michel Pêcheux. Como espinha dorsal, utilizamos autores, tais como, as obras de Ramos (2008), Frigotto (2012; 2015), Ciavatta (2005) e Machado (2006) para embasamento da discussão teórica da relação entre o trabalho, educação e ensino médio integrado. De um modo geral, pode-se intuir que as discussões teóricas efetuadas e as análises demonstram que os sentidos dos termos "integração" e "cursos técnicos ao ensino médio integrado" são expressões polissêmicas e retratam diversas práticas político-pedagógicas para além das questões atinentes ao currículo das disciplinas propedêuticas e técnicas.
\end{abstract}

Palavras chave: Ensino médio integrado. Trabalho como princípio educativo. IFNMG - Campus Almenara.

Abstract: This research is an excerpt from the dissertation of the professional master's program in technological education at the IFTM - Campus Uberaba-MG and, aims to analyze, through the speeches of the subject-professors active in the technical courses integrated to the high school of the IFNMG Campus Almenara, the meanings of "integration" and "technical course integrated to high school". With regard to the theoretical-methodological design, the research has a qualitative approach, semi-structured 
interviews are used as a data collection instrument having six subject-teachers participating in the research who work in one of the technical courses integrated to high school in the referred institution. We are based on the assumptions of Discourse Analysis (henceforth AD) of French line, in the light of the episteme of the thinker Michel Pêcheux. As a backbone, we use authors, such as the works of Ramos (2008), Frigotto $(2012,2015)$, Ciavatta (2005) and Machado (1991; 2006) to support the theoretical discussion of the relationship between work, education and integrated high school. In general, it can be intuitive that the theoretical discussions carried out and the analyzes demonstrate that the meanings of the terms "integration" and "technical courses for integrated high school" are polysemic expressions and portray several political-pedagogical practices in addition to the issues involved curriculum of propaedeutic and technical disciplines.

Keywords: Integrated high school. Work as educational principle. IFNMG - Campus Almenara.

Resumen: Esta investigación es un extracto de la disertación del programa de maestría profesional en educación tecnológica en el IFTM - Campus Uberaba-MG, y tiene como objetivo analizar a través de los discursos de los sujetos profesores actuantes en los cursos técnicos integrados en la escuela secundaria del IFNMG - Campus Almenara, los sentidos de "integración" y "curso técnico integrado al bachillerato". La investigación tiene un enfoque cualitativo. Se utiliza como instrumento de recopilación de datos entrevistas semiestructuradas con el cuantitativo de seis sujetos profesores que actúan en uno de los cursos técnicos integrados en la escuela secundaria en la citada institución. Nos basamos en los supuestos del Análisis del Discurso (en adelante AD) de la línea francesa, a la luz del episteme del pensador Michel Pécheux. Como espina dorsal, utilizamos autores, como las obras de Ramos (2008), Frigotto (2012; 2015), Ciavatta (2005) y Machado (1991, 2006) Para apoyar la discusión teórica de la relación entre el trabajo, la educación y la escuela secundaria integrada. En general, se puede intuir que las discusiones teóricas realizadas y los análisis demuestran que los significados de los Los términos "integración" y "cursos técnicos para la escuela secundaria integrada" son expresiones polisémicas y representan diversas prácticas políticas y retratan varias prácticas político-pedagógicas más allá de las cuestiones relacionadas con el currículo de las disciplinas propedéuticas y técnicas.

Palabras clave: Escuela secundaria integrada. El trabajo como principio educativo. IFNMG - Campus Almenara.

\section{Introdução}

As concepções e práticas educativas relacionadas ao debate que permeia as discussões sobre a tônica do trabalho enquanto princípio educativo, a partir de uma perspectiva histórica, filosófica e sociológica têm suas abordagens de reflexões mediadas pelos pressupostos ancorados na técnica, educação, ciências e tecnologias. Nesse sentido, a formação profissional integrada ao ensino médio tem sua representação ligada aos processos formativos que dialogam com o mundo do trabalho, e o ensino médio em si mesmo revela-se um veemente campo de disputas sobre que sujeito formar. Sob essa perspectiva, a formação profissional de nível médio historicamente está vinculada a uma perspectiva mercadológica-industrial, ligada às práticas formativas educacionais do competitivo mundo do trabalho, "as relações sociais e produtivas em cada regime de acumulação" (GRABOWSK; KUENZER, 2016, p.24). 
Portanto, essa vertente de reflexão fundamentada na perspectiva de qualificação de trabalhadores, decorrente das transformações resultantes da revolução industrial em plena era da informática e automação muda o desenvolvimento do processo produtivo e as relações do homem e da máquina na sociedade. Esse fenômeno rompe a lógica da formação escolar vista enquanto um princípio do direito social, instaurando-lhe uma finalidade econômica em detrimento da formação para cidadania. Nesse sentido, ao refletir sobre a noção de competências na relação trabalho e educação, é nítido compreendermos a educação como promotora do desenvolvimento econômico, face o discurso da noção da teoria do capital humano, a partir da ideia de pedagogia das competências (FRIGOTTO, 2015).

Nesse sentido, faz-se necessário (re)pensar a educação sob a ótica das diversas transformações sociais pelas quais o mundo do trabalho vem passando, pois as mudanças que perpassam os avanços tecnológicos sempre existiram na história da humanidade, contudo mormente ao longo das últimas décadas, têm se intensificado, causando novas leituras e sentidos da realidade, modificando sobremaneira as expectativas das instituições educacionais. Nessa maneira, o desenvolvimento industrial e tecnológico impacta as relações e processos de produzir os bens de consumo, agir e pensar, consequentemente esses processos estabelecem novos diálogos da educação com as relações de trabalho e a escolarização.

Mediante a efervescência da aprovação do Decreto $n^{\circ}$ 5.154/2004, do governo Lula, reacende, no cenário nacional, a discussão da relação trabalho e educação, a partir da perspectiva de integração curricular entre o ensino médio e a educação profissional que busca uma proposta curricular e que visa integrar o conhecimento da formação propedêutica ao conhecimento específico da formação profissional em um currículo unitário. Nessa lógica, é comum considerar que os conhecimentos curriculares de base técnica estão ligados à prática de determinada atividade, compreendida como saber-fazer. Ao passo que os conhecimentos de base teórica são compreendidos de maneira desarticulada das atividades laborais, restringindo a formação restrita ao saber-pensar. Assim, percebe-se que há uma dualidade do conhecimento em áreas do saber prático e teórico, colocados historicamente em oposição a escola unitária (FRIGOTTO; CIAVATTA; RAMOS, 2010).

Nesse contexto, essa pesquisa como um estudo de caso, ancora-se pela relevância em desvelar as narrativas/enunciados dos sujeitos-professores, nas questões pertinentes a concepções e sentidos do ensino médio integrado vinculadas às reflexões sobre as práticas de ensino integradas desenvolvidas nesse nível de ensino. Tais análises têm sido despertadas em minha práxis, enquanto servidor de carreira técnico-administrativo de nível superior, ocupante 
do cargo de pedagogo no Instituto Federal do Norte de Minas Gerais - IFNMG - Campus Almenara.

A pesquisa fundamenta-se nos pressupostos da metodologia qualitativa, tendo como instrumento de pesquisa entrevistas semiestruturadas. Os discursos serão analisados à luz da vertente crítica da teórica da Análise do Discurso (doravante AD) de linha francesa, tendo como espinha dorsal a episteme do pensador Michel Pêcheux para buscar os sentidos que permeiam os enunciados dos sujeitos-professores que atuam no ensino médio integrado à formação profissional técnica. O universo da pesquisa original da dissertação, constituiu-se de um quantitativo de oito sujeitos entrevistados, embora neste artigo utilizaremos o recorte das discussões teóricas e das entrevistas de seis deles, sendo os excertos das entrevistas dos participantes número $1,2,3,5,7$ e 8 .

A pesquisa realizou-se com quatro sujeitos-professores que atuam nas disciplinas de formação geral e dois sujeitos-professores que atuam nas disciplinas de base de formação específica de área técnica profissional que lecionam em pelo menos um dos cursos integrados à formação profissional ofertados pela instituição, a saber: o curso técnico integrado em agropecuária, informática, zootecnia, administração e agropecuária no regime de alternância. As entrevistas foram selecionadas e agrupadas de maneira separadas e procedeu-se de acordo com a ordem das questões interpeladas aos entrevistados.

Posto isto, para análises dos enunciados utilizou-se trechos das entrevistas que respondem de forma clara e objetiva à ideia das questões indagadas e que vão ao encontro dos objetivos que compõe o corpus da pesquisa para fundamentar a discussão. Utilizou-se como critério de inclusão ser professor do quadro permanente no IFNMG - Campus Almenara, e consequentemente, tem-se como critérios de exclusão da participação da pesquisa ser professor contratado ou temporário. Além disso, a relevância dessa pesquisa justifica-se, por trabalhar em uma instituição pública da Rede Federal de Educação Profissional, Cientifica e Tecnológica ${ }^{1}$ que conjuga em concepção os conhecimentos técnicos e tecnológicos com as suas práticas pedagógicas, somos levados a repensar cotidianamente o nosso fazer político e pedagógico.

Contudo, a gênese da concepção desse projeto de pesquisa foram as constantes incongruências conceituais e metodológicas observadas nos projetos pedagógicos dos cursos de nível médio integrado à educação profissional e a reprodução do desenho convencional das disciplinas em suas matrizes curriculares. Assim, esta pesquisa buscou-se analisar, por meio

\footnotetext{
${ }^{1}$ Criada em 2008 pela Lei no 11.892, de 29 de dezembro, a Rede Federal de Educação Profissional, Científica e Tecnológica, também conhecida por Rede Federal, constitui-se em um marco na ampliação, interiorização e diversificação da educação profissional e tecnológica no país.
} 
dos discursos dos sujeitos-professores atuantes nos cursos técnicos integrados ao ensino médio no IFNMG - Campus Almenara, os sentidos de "integração" e de "curso técnico integrado ao ensino médio".

\section{Ensino médio e o mundo do trabalho}

Um dos principais desafios da educação na atualidade consiste no estabelecimento do sentido do ensino médio e, que, em sua representação social, ainda não respondeu aos objetivos que possam ser considerados para além de uma mera passagem para o ensino superior ou para a inserção no mundo do trabalho (SIMÕES, 2010, p.116). Sabe-se, porém, que trabalho e educação são entendidos como práticas sociais que se estruturam na problemática do mundo do trabalho compreendendo-o como unidade de uma relação dialética e antagônica entre educação e a articulação com os sistemas produtivos.

Desse modo, o ensino médio pretende configurar sua identidade como etapa final da educação básica mediante um projeto que seja unitário em seus princípios, objetivos e suas abordagens didático-metodológicas, objetivando superar a dualidade histórica presente em nosso sistema educacional que opõe a educação propedêutica com a educação profissional no sistema educacional brasileiro, e que cria trajetórias educacionais diferentes de acordo com as estruturas de classes sociais, opondo a educação de formação geral à educação profissional.

De tal sorte, a educação escolarizada constitui-se uma estrutura dual de ensino, caracterizada por formas e organização diferentes e paralelas que não se complementam, separando-as entre níveis e modalidade de ensino, segmentando os conhecimentos gerais em níveis de ensino, de caráter propedêutico dos conhecimentos tácitos em modalidade voltados para prática da formação profissional instrumentalizada. Não obstante, ao tratarmos da dualidade no sistema de ensino, faz-se necessário compreender suas razões éticas, políticas e pedagógicas com o intuito de defendermos uma proposta de educação geral de nível médio integrado à formação profissional.

As discussões em torno do dualismo na educação brasileira constituem um tema amplo, complexo, e envolve estruturas sociais preexistente, ligado ao nosso sistema de colonização agroexportador. Nesse sentido, é consensual o fato do ensino médio revelar-se a maior expressão dessa segmentação educacional. De acordo com Frigotto, Ciavatta e Ramos (2012, p.31),

É nesse nível de ensino que se revela com mais evidência a contradição fundamental entre o capital e o trabalho, expressa no falso dilema de sua identidade: destina-se à formação propedêutica ou à preparação para o 
trabalho? A história nos permite maior clareza sobre a questão, porque vai revelar a ordenação da sociedade em classes que se distinguem pela apropriação da terra, da riqueza que advém da produção social e da distribuição dos saberes.

Além disso, o ensino médio é um nível de ensino que não percebe ou podemos dizer que nega a pluralidade das ideias e sonhos juvenis como sujeitos históricos sociais que desenvolvem sua identidade pautada em trajetórias pré-determinadas, prioritariamente, pelo sistema de produção econômico para atender à lógica de mercado. Sob esse olhar, a formação cidadã pensada pela ótica da compreensão da totalidade em todas suas dimensões, transformouse em escolarização para o trabalho, sendo percebida, no senso comum, como o lugar de formar - ação alienante - para o mundo do trabalho, numa perspectiva restrita e segmentada de perceber a educação como treinamento e qualificação profissional.

Nesse sentido, em Moura (2007) podemos constatar que na história da educação brasileira, a relação entre a educação básica e a profissional é marcada pela concepção dualista, a serviço da manutenção das estruturas de classe. Dessa maneira, o ensino médio configura-se como importante etapa de formação e representação do trabalho a partir dos fundamentos e princípios educacionais de relacionar o conhecimento em sua totalidade no mundo da vida e não somente ligada à concepção de produção.

Assim, a compreensão da expressão trabalho é muito mais ampla que o sentido que a sociedade moderna apregoa. O trabalho desponta como um princípio educativo, ou seja, antecede a compreensão limitada à formação profissional e tecnicista de operar os meios de produção. Nessa perspectiva, o trabalho é concebido no sentido de intervenção do homem na natureza e "ser" por excelência produtor da sua existência, por meio das técnicas. Assim, como produtor de cultura o homem cria sua realidade com a ação de intervir na natureza.

Ao tratar da formação integrada, é nítido que, no centro do debate, está a abordagem de modelos educacionais divergentes que estão em constantes atritos, em um jogo de forças e poder político, econômico, cultural e ideológico. Não obstante, Araújo e Rodrigues (2010) apontam que a educação constitui campo de disputa e que esse modelo antagônico pode transitar com ideias antagônicas, podendo vir a ser para conformação à realidade ou para transformação social.

Dessa maneira, urge um modelo de educação e ensino que demonstre que o poder de transformação da educação está assentado na conscientização do homem e da mulher no contexto em que estão inseridos, podendo ter condições de fazer a leitura do mundo para transformar a realidade e libertar das amarras das estruturas dominadoras e opressoras de classe. 
Nesse sentido, Ramos (2008) esclarece que as dimensões formativas atribuídas ao ensino médio precisam se fundamentar em concepções humanitárias que cumpram o papel que a sociedade espera para cada tempo e espaços sociais, ou seja, o ensino médio precisa reinventar-se.

[...] é preciso que o ensino médio defina sua identidade como última etapa da educação básica mediante um projeto que, conquanto seja unitário em seus princípios e objetivos, desenvolva possibilidades formativas que contemplem as múltiplas necessidades socioculturais e econômicas dos sujeitos que o constituem - adolescentes, jovens e adultos -, reconhecendo-os não como cidadãos e trabalhadores de um futuro indefinido, mas como sujeitos de direitos no momento em que cursam o ensino médio. (RAMOS, 2008, p.6)

Pode-se perceber que as imagens desse nível de ensino estão em constante vicissitude, acompanhando o homem e suas necessidades ao longo do tempo histórico, na busca daquilo que é próprio da condição humana - o processo histórico de sua formação.

Nesse sentido, ao discutir sobre o diagnóstico da educação, Machado (1991, p.22) aponta que "a crise do Estado brasileiro jogou o sistema nacional de educação no fundo do poço, criou mecanismos de desigualdade não só social". O modelo de educação como é conhecido é seriamente posto em questão, pois traz um retrato constrangedor, uma vez que dados mostram os índices alarmantes de excluídos desse projeto de cidadania. No decorrer dessas reflexões a autora em tela defende que está cada vez mais convencida de que "é na escola média que está o calcanhar de Aquiles" do sistema educacional, que não tem uma identidade consolidada no que diz respeito à finalidade da formação ofertada aos jovens. (MACHADO, 1991, p.48)

A proposta do ensino médio integrado à educação profissional tem ocupado o centro dos espaços de debates da educação brasileira. As Diretrizes Nacionais para o Ensino Médio, ao abordarem a identidade desse nível de ensino, dispõem que "um dos principais desafios da educação consiste no estabelecimento de significados do Ensino Médio”, garantindo as dimensões da formação que englobam a perspectiva do trabalho, a ciência, a tecnologia e a cultura para compreensão das relações sociais e produtivas, buscando aproximar a escola da realidade. (BRASIL, 2013, p. 170)

É importante construir uma identidade para o ensino médio, consolidando-o, mediante convergência com os avanços do conhecimento científico e tecnológico, vinculando a compreensão das ciências como ato prático da vida, proporcionando formas para esses sujeitos fazerem as leituras da realidade, numa perspectiva de sua emancipação, fundamentada em uma postura crítica e epistemológica. Nesse contexto, necessita-se, pois, de uma formação integrada para dar sentido ao ensino médio, possibilitando vislumbrar a tão sonhada condição de acesso, 
permanência e êxito dos jovens trabalhadores no contexto da educação básica de qualidade e para todos, independentemente de sua posição social e econômica.

\section{O sentido do ensino médio integrado}

Ao discutirmos sobre os pilares que fundamentam a formação do Ensino Médio Integrado, temos que perceber as dimensões do trabalho enquanto processo educativo, tendo como referência que a educação ancora-se no trabalho, ciência, tecnologia e cultura para dar conta do processo de desenvolvimento civilizatório da humanidade. Sabemos que as discussões em torno do ensino médio integrado ainda não concretizaram suas ideias na prática do fazer pedagógico nas escolas, revelando um projeto inconcluso e distante das concepções de quem pensa o projeto e quem executa a integração no "chão das escolas", ainda cheio de incongruências.

A partir dessa compreensão, Araújo e Frigotto, inspirados nos estudos de Costa (2012), revelam que há muitos impedimentos no que tange ao projeto de Ensino Médio Integrado, que vão além das condições materiais. Para este pesquisador, o principal dificultador para concretização do Ensino Médio Integrado assenta-se na definição conceitual, na operacionalização curricular e na organização dos sistemas de ensino. Constatam que o Ensino Médio Integrado não foi assimilado como um projeto político-pedagógico, anuncia que a proposta da forma de oferta do ensino médio integrado não tem sido compreendida numa dimensão totalizante, ficando presa a uma compreensão conceitual e prática limitada.

Contudo, esse pensamento fica restrito a um fazer didático presente num currículo prescrito que não dialoga com o conhecimento escolar com a função do trabalho como princípio educativo. Não obstante, o que se observa é que o ensino integrado tem sido entendido de maneira restrita ao plano didático direcionado às estratégias e à organização dos conteúdos escolares. No entanto, concebe-se que a ação didática integrada deve voltar à práxis, como atividade de transformação de circunstâncias, tendo a relação da teoria e a prática como processo único que juntos se retroalimentam numa ação mútua e recíproca (ARAÚJO; FRIGOTTO, 2015, p. 65).

Analisando sob esse enfoque, Ciavatta (2005), ao tratar da formação integrada, destaca que o conceito transcende as práticas do aprender a fazer da ação do homem no mundo pela sua ação na natureza por meio do trabalho no sentido amplo do termo, proporcionando a compreensão de que a formação integrada supera a visão restrita do ser humano decomposto historicamente pela divisão social do trabalho. Nesse alinhamento de concepções, Nosella (2007, p.148), citando Marx, reafirma que o "trabalho é fundamentalmente interação dos 
homens entre si e com o mundo". Por isso, utiliza também a expressão, a "escola-do-trabalho". Assim, postula que na formação integrada o conhecimento técnico-científico apropriado histórica e socialmente pelo homem ocupa a gênese do processo produtivo. Assim, o homem ocupa o cerne da formação integrada no mundo e com o mundo, integrando a formação geral aos fundamentos das ciências, cultura e das técnicas.

Defendendo a educação de natureza politécnica, Ramos (2008, p.2-3) sintetiza os sentidos a que o trabalho remete.

O trabalho no seu sentido mais amplo, como realização e produção humana, mas também o trabalho como práxis econômicas. Com isto apresentamos os dois pilares conceptuais de uma educação integrada: um tipo de escola que não seja dual, ao contrário, seja unitária, garantindo a todos o direito ao conhecimento; e uma educação politécnica, que possibilita o acesso à cultura, à ciência, ao trabalho, por meio de uma educação básica e profissional.

Para tanto, é fundamental levar em conta as noções dos principais conceitos abordados que envolvem as dimensões da formação humana, tendo como suporte o trabalho, ciência, tecnologia e cultura, como dimensões nucleares para se pensar a dimensão integral da vida do educando numa etapa tão importante de formação da educação básica, indispensável à concepção científica da vida.

Nesse sentido, entende-se que o trabalho é definido sob o prisma ontológico de transformação da natureza como ação inerente ao ser humano que, ao interferir, modifica os processos de sua existência e, sendo assim, produz a cultura. $\mathrm{O}$ trabalho também tem o sentido teleológico, que se constitui na ação consciente do ser humano sobre o meio material para satisfazer suas vontades e necessidades, de modo a transformar a realidade.

Esse modo de produzir o conhecimento historicamente sistematizado constitui a ciência como se conhece, produção conferida através de método de análise para se apropriar conceitualmente dos fenômenos naturais. Por exemplo, a descarga elétrica, os raios, sempre existiram, e ao serem teorizados impulsionam, isto é, podem revolucionar os avanços das forças produtivas (RAMOS, 2008). Entende-se, portanto, que a ciência pode ser considerada um conjunto de conhecimentos, produzidos e legitimados ao longo da história, que busca compreender e transformar a natureza e a sociedade por meio de novos conhecimentos.

Dessa maneira, faz-se necessário esclarecer que em uma perspectiva de formação unitária, eclodem os pressupostos e princípios educativos de uma educação politécnica para a classe trabalhadora, preconizada por Marx, na qual integra a educação intelectual, educação corporal e educação tecnológica, tendo como mola propulsora o trabalho, ciência, tecnologia e cultura para superação da dualidade ou sobreposição do trabalho intelectual sobre o trabalho 
manual, buscando a transformação social pela classe trabalhadora por meio do domínio das artes, as letras e as ciências para que aconteça um efetivo exercício de emancipação e cidadania.

Para Machado (2006), a tecnologia pode ser compreendida como transformação das ciências em forças produtivas. Portanto, ao longo da história, pode-se perceber que o desenvolvimento da tecnologia ganhou conotação utilitarista. A tecnologia é também entendida como meio de produção que se constitui por meio da intervenção na realidade. Por sua vez, a cultura, no sentido mais amplo da expressão, pode ser entendida como conjunto de representações, comportamentos, processos e relações sociais que orientam as normas de conduta e expressões estéticas. Pensando de forma atrelada, esses conceitos formam uma percepção da totalidade, a partir daí que a cultura engloba todos os modos de representar a realidade.

Desta maneira, pode-se compreender que a junção das ciências, tecnologia e cultura representa a realidade de forma integrada. Assim, a formação integrada é complexa e perpassa por diversas dimensões da vida, tendo o trabalho como mola propulsora, atento aos processos, tempos e espaços históricos. Com isso, pode-se compreender que a base da proposta do Ensino Médio integra as dimensões histórico-filosóficas da formação humana, tendo como âncora o trabalho, a ciência, a tecnologia e a cultura para constituir a estrutura curricular, dando sentido ético-social ao conhecimento. Nesse viés, o conhecimento é o cerne do trabalho pedagógico, materializado nas ações de produção histórica e cultural articuladas com diversos interesses.

\section{Resultados da pesquisa}

Ao abordarmos a discussão acerca dos sentidos que os sujeitos-professores concebem ao ensino médio e sua representação social, podemos notar pelos enunciados que essa é uma fase do processo formativo para a vida em sociedade. Isto é, o ensino médio apresenta especificidades que lhes são próprias na materialidade desse nível de ensino e as expectativas criadas pela sociedade capitalista faz dele um campo de forma[ação] muito disputado. Ademais, percebe-se que as posições dos entrevistados são divergentes, mesmo reconhecendo sua relevância social, apontam que sua finalidade precisa ser melhor debatida, tendo como dilemas a bifurcação da formação para cidadania ou formação para atender à ótica do mercado de trabalho.

Assim, a complexidade desse debate reside na concepção de que o ensino médio é recente na história da educação e é marcada por uma complexa construção identitária que tem sua importância e valor na sociedade brasileira, principalmente entre as camadas mais pobres; que sua representação está associada como espaço de privilégios e não de direitos; que vê esse 
nível de ensino como possibilidade de ascensão social para o trabalho ou para a formação destinada para a aprovação em vestibulares.

Nessa vertente, percebe-se que está entranhado na cultura brasileira o pensamento de uma herança colonial marcada pela desigualdade de ordens social, econômica e educacional que, consequentemente, acaba refletindo a representação social desse nível de ensino. Nesse sentido, essa perspectiva do ensino médio fragmentada é legitimada pela sociedade que não reivindica um processo formativo em uma perspectiva de formação integral do sujeito. Destarte, constata-se que o EM tem suas marcas históricas permeadas pelo dualismo educacional, viés formativo diferente, conforme as estruturas de classe social. Assim, para os filhos das elites a formação escolar ofertada é uma formação abrangente de domínio do conhecimento intelectual próprio da classe de dirigentes e para os filhos dos trabalhadores é ofertado um ensino reducionista ligado às atividades manuais. Dessa maneira, ambos os processos têm em comum negar o trabalho como um princípio educativo.

[...] eu acho que a representação social do Ensino Médio e mais do que do Ensino em si, o título do Ensino Médio ela é ainda muito relevante, valorizada na sociedade brasileira. As famílias ainda consideram um valor sobretudo as famílias de mais baixa renda, [...] traz relevância para essas pessoas na sociedade e há uma vantagem interessante, vários empregos sobretudo públicos têm como pré-requisito o Ensino Médio. Então, eu acho que do ponto de vista da representação social, o Ensino Médio, ele tem muito valor. Por outro lado, quando a gente pensa no Ensino Médio, O Ensino médio, ele é uma espécie de - hoje em dia embora ele seja consolidado e sua importância, veja ela não é discutida, mas ela não é indiscutível, percebe? É... [...] na nossa sociedade ninguém discute hoje se ele é relevante ou não- Pessoalmente, eu vejo o Ensino Médio no formato positivista herdado do início do século, ele tem muito pouco sentido na vida das pessoas e eu percebo que poucos alunos valorizam o curso por sua proposta científica e pelo seu formato. (ENTREVISTADO n ${ }^{\circ}$ )

[...] o Ensino Médio é uma das fases mais importantes em termos de educação para a formação cidadã do aluno. Então, nós temos o EF que dá uma base de conhecimento e de informação em termos de escolaridade. O Ensino Médio, ele vai aprofundar essa base de conhecimento, né? Que o aluno traz do Ensino Fundamental e, além disso, tem a complementação da formação cidadã. [...]. Ele já tem uma compreensão de mundo, de valores, e é um momento importante também de decisão para o mercado de trabalho. Aprofundamento de conhecimento, formação cidadã, e um olhar para o mercado de trabalho. Por isso que eu acho que é uma fase crucial [...] pro aluno no geral. É uma fase muito completa e, ao mesmo tempo, muito complexa, que ele tem que lidar com muita novidade e, ao mesmo tempo, ele tem que saber [...] é tomar decisões que são importantes para o seu futuro. (ENTREVISTADO n³)

Nesse sentido, o ensino médio enquanto processo de escolarização configura-se como nova oportunidade de aprofundamentos conceitual e atitudinal, sendo concebida sua formação numa perspectiva emancipatória. Todavia, como nos aponta o entrevistado $\mathrm{n}^{\mathrm{o}} 2$, “eu percebo 
que poucos alunos valorizam o curso por sua proposta científica e pelo seu formato". Isto nos chama atenção pelo fato dos discursos assinalarem para a perspectiva de os alunos darem prioridade à formação propedêutica em detrimento da formação profissional. Assim, essa perspectiva distorce a concepção da formação do ensino médio integrado como forma de superação da divisão da realidade no que tange ao conhecimento teórico-prático.

Dessa maneira, percebe-se a ênfase na construção da identidade do sujeito que está em formação para poder atuar como cidadão produtivo, visto que não valorizar e reconhecer a formação pelo seu formato ou proposta científica significa que qualquer proposta formativa serve, ou seja, o sujeito está alienado do seu processo formativo. Contudo, essa fala evidencia desconhecimento sócio-histórico em relação à proposta formativa educacional, e isso impossibilita reconhecer a educação como campo de disputa e poder.

Observa-se que o ensino médio é tido como uma travessia de um processo formativo que nega o sujeito de direito no momento presente e coloca-o na condição do devir a se formar enquanto cidadão. Desse modo, a educação serve para moldar as atitudes dos sujeitos juvenis para encarar/reproduzir a vida adulta, como cidadãos subordinados para atender à ordem vigente de sujeito que está sendo formado para ocupar lugares e espaços sociais a partir do viés do trabalho, por meio da formação escolar para atender à lógica do mercado de trabalho. Nesse processo, o ensino médio incorre de maneira fragmentada dos demais níveis de ensino como o último nível da educação básica e como meio para se chegar ao ensino superior.

[...] eu ainda acho que, do ponto de vista da representação social, o EM ainda é, digamos assim, o estágio de passagem para a Universidade. (...) Percebo que as famílias como hoje o acesso à Universidade cresceu muito, o EM ficou sendo esse meio-termo, né? Então fica lá três anos e depois já se espera que o estudante complete sua formação. Então, antigamente, talvez esse seja o caso, que antes a pessoa tinha o EM como se quase tivesse quase que completado né. Pra ela já poder entrar ou ingressar no mercado de trabalho. Como hoje a exigência é um pouco maior, principalmente nos campos de chefia que tem um salário mais elevado, a tendência é exigir que o estudante, o jovem tenha o acesso ao ensino superior, e aí fica um pouco essa ideia no imaginário social de que o EM está ali pra preparar um pouco o estudante para entrar na universidade. [...] Então, do ponto de vista da representação social, esse EM é essa passagem que está ali, ele sai do fundamental e aí no EM ele vai aprofundar alguns conteúdos pra conseguir esse acesso ao Ensino Superior. (ENTREVISTADO $\mathrm{n}^{\circ} 1$ ).

Nessa acepção, observa-se que a realidade brasileira na qual parte significativa da população constitui-se de trabalhadores, o EM é concebido numa perspectiva de sobreposição da formação para servir à lógica de mercado em detrimento da formação de uma cultura geral e propedêutica destinada para os filhos das classes trabalhadoras. Nesse arranjo, o processo 
formativo do EM aponta para itinerários formativos divergentes e antagônicos, de acordo as classes sociais, numa perspectiva de um ensino dual presente na sociedade capitalista.

Segundo os discursos enunciados, o ensino médio é apresentado como um meio para o acesso ao ensino superior, voltado para os filhos das elites ocuparem as atividades intelectuais e de gerência na sociedade. Nesse sentido, o ensino médio é colocado como instrumento de reprodução do status quo da elite proprietária dos meios de produção que necessita da força de trabalho das classes subalternas. Assim, para os filhos do proletariado tem-se um ensino voltado para as atividades ligadas ao trabalho manual, do "saber-fazer".

Nesse sentido, o ensino superior é visto a partir de uma ótica excludente, uma vez que o acesso a esse nível de ensino não é universal e desvela-se como objeto de desejo no imaginário social para os sujeitos ocuparem melhores postos de trabalhos. Assim, presume-se que quem estudar mais tem maiores possibilidades de ocupar postos de trabalhos com maiores prestígios sociais. Desta maneira, percebe-se que o capitalismo tem se apropriado da estrutura educacional e dela se servido.

Ao serem questionados se no entendimento dos sujeitos-professores o ensino médio atualmente faz sentido, percebe-se que não há um consenso sobre o assunto, uma vez que os sujeitos-professores trazem à tônica argumentos divergentes para embasarem suas respostas, atentando sobre o papel social da educação e sua representação social na sociedade atual que é marcada pela era das tecnologias da informação e do conhecimento. Isso evidencia que se coloca em questão a quebra de paradigmas das velhas estruturas de ensino tradicional pautado na transmissão de conhecimentos anunciada pelos docentes. Tal posição desperta uma reflexão acerca dos objetivos da existência do ensino médio, levando em conta a singularidade desse nível de ensino em meio à pluralidade e complexidade do que se espera do processo formativo específico do EM na sociedade contemporânea.

Contudo, as narrativas aludidas remetem ao entendimento que compreende a formação escolar referente ao ensino médio para além do acesso ao ensino superior. Pensando a partir dessa premissa, como mencionado pelo entrevistado $n^{\circ} 8$, "todo ensino faz sentido", o que coloca em questão é a forma e os meios de interlocução do conhecimento. Nesse sentido, os processos de ensino e aprendizagem são sempre atuais nos debates educacionais.

[...] o EM ele tem o sentido que é o sentido mais formativo e existe essa especificidade da formação do EM que é diferente tanto do fundamental quanto do superior. É, e aí a gente fica um pouco pensando nesses objetivos mais essenciais do EM por um lado, mas por outro lado, também, a pressão dessa representação social faz com que muitas vezes a gente também trate o EM como travessia. Então, acho que tem um sentido, mas ele não é totalmente, digamos, é contemplado, seja pela instituição de ensino, seja pelo modo como 
os professores agem, seja mesmo como o modo com que os alunos esperam, né? Então eu penso essas duas coisas, elas acabam, elas não são totalmente contraditórias, mas em muitos pontos elas acabam digamos se "excluindo" [...]. (ENTREVISTADO no 1 )

Eu acredito que o formato do Ensino Médio ele faz sentido. Algumas vezes nós enquanto docentes temos algumas falhas. É, em que sentido? É, por exemplo, às vezes, a gente tende a ensinar ficar muito preocupado, é [...] em ensinar os alunos sobre as avaliações externas. Então, há uma cobrança muito grande sobre as avaliações externas. Ah, você tem que estudar bastante porque você vai tentar o ENEM... Ah, você tem que estudar bastante porque você tem que se preocupar com o Vestibular. E em alguns momentos essa preocupação com avaliação externa ela sobrepõe a formação cidadã. (ENTREVISTADO $n^{\circ} 3$ )

Bom, creio que todo ensino ele faz sentido. Não é porque nós dividimos o ensino básico em ensino fundamental e ensino médio que o ensino médio tenha um sentido diferente do fundamental. [...], o ensino é um ciclo, então, em todas as fases é importante. Todas as fases fazem sentido. Agora, é [...], na minha concepção como educador, né, o sentido maior é quando a gente percebe que existe um, um link entre essas duas partes, né, do ensino básico, ensino fundamental com o médio, né? Faz pleno sentido por que é justamente no momento que o aluno ele está saindo, né, da adolescência praticamente pra começar a entrar numa vida adulta. (ENTREVISTADO nº)

Contudo, constata-se que os sujeitos-professores que se posicionam contrários à forma de conceber os sentidos do ensino médio, são categóricos ao afirmarem que a forma de oferta do EM não faz sentido, uma vez que não correspondem à leitura objetiva da realidade, mas incorre como método de ensino anacrônico em nosso tempo. Ou seja, ele não dá conta de acompanhar as transformações científicas e tecnológicas que acabam modificando as relações sociais e os processos de ensino e aprendizagem.

Nesse sentido, apontam que na sociedade globalizada com o uso da internet mudou-se a forma de ensinar e aprender e não faz mais sentido tratarmos o conhecimento de forma isolada e fragmentada como possibilidade de aprofundamento. Nesse sentido, o ensino médio como repetição e aprofundamento do conteúdo curricular estudado no ensino fundamental e como possibilidade de se fazer a travessia para o mundo do trabalho não faria mais sentido na atualidade. Dessa maneira, o EM é visto de forma a criticar as "velhas estruturas" que concebem que o conhecimento precisa ser anunciado em formato de aula para uma coletividade no modelo das escolas tradicionais. Assim, percebe-se que o currículo engessado é desinteressante, descontextualizado e constituído de um processo formativo cheio de rupturas, dividido em níveis de ensino.

[...] ele não faz sentido. Eu percebo que existem diversas disciplinas, diversos conhecimentos que são divulgados que hoje são muito facilmente acessíveis por pessoas que têm acesso à internet - desde que elas saibam ler e escrever e manusear instrumentos digitais - eu vejo que o Ensino Médio há muita 
repetição de temas que foram tratados no Ensino fundamental; eu vejo que os temas tratados no Ensino Médio, eles são de desinteresse geral dos alunos, não é? Nós vivemos hoje numa sociedade extremamente interconectada globalizada em que a utilidade das coisas [...], ela tem sido muito mais valorizada, então um conhecimento que não faz sentido, uma informação que não faz sentido, um tempo gasto sem sentido, ele não tem valor, e no nosso Ensino Médio hoje nós é, preconizamos, o ensino de temas que já vêm, é, como diz Rubem Alves, uma absurda grade curricular, que parece mais uma cadeia, e ele tem pouca abertura pra [...] interferência do aluno e ele não traz temas que são de interesse dos estudantes e que, ao mesmo tempo, são capazes de contribuir pra uma vida em sociedade mais plena. (ENTREVISTADO n²)

Nesse ínterim, o entrevistado $\mathrm{n}^{\mathrm{o}} 5$ faz uma reflexão no que diz respeito às palavras e suas nomenclaturas, pois elas carregam um sentido além de etimológico: o seu sentido histórico: outrossim, nos faz provocações da justificação da existência do EM como meio-termo em relação ao processo de travessia do ensino fundamental para a Universidade. Assim, questiona as estruturas e a organização do ensino que concebe a educação básica em etapas formativas. Defende a educação básica em ciclos de formação, não podendo ter rupturas no processo de formação da educação básica. Assim, o EM não pode ser concebido como transição do EM para a Universidade.

Porventura, quando pensamos no ensino médio temos que refletir que ele é médio em relação a qual etapa da formação escolar? Ou o ensino médio tem como finalidade formar o cidadão para ocupar espaços do mundo do trabalho? Pode-se notar que o ensino médio sofre dilemas e influências da formação que o mundo do trabalho exige desse cidadão. Por isso, os processos formativos desses sujeitos são disputados a partir da lógica do trabalho para a empregabilidade.

Não. Não faz sentido. Não, se a gente mantém a percepção separada. Eu gosto muito de pegar o modelo português. [...]. Educação básica, você não tem ruptura. Óbvio que, em determinado momento, a pessoa faz escolhas no seu processo formativa da educação básica, ou quer seja ampliar a sua ação de humanas, biológicas, exatas [tosse] por isso que você, $\mathrm{o} 13^{\circ}$ ano que seria, que seria o $12^{\circ}$, que seria o ano de formação para acesso à Universidade, né? Pensando aí que aos 14 anos, a pessoa já tem uma certa maturidade para se aprofundar em determinadas áreas por interesse. [...] Acho que esse, esse movimento de pensar em ciclo de formação básica é mais interessante do que pensar a existência de ensino médio, né? Acho que é a gente mantem um termo mais pra tradição. [...], mas não há reflexão [...] real sobre o porquê dessa separação; você tem ali um texto, olha, etapa final da formação da educação básica - ponto. [...] Por que essa separação desse jeito? Por que ainda é [...] há uma representação de que você - aqui é o Fundamental, e aqui é o médio. O médio em relação ao que? Médio em relação à graduação, ou seja, você tá no limbo. O ensino médio ainda é visto como um limbo do ponto de vista instrumental, [...], mas a gente não avançou o suficiente como reflexão sobre como esse direito deve ser pensado como formação continuada, e não como formação de ruptura. (ENTREVISTADO n5) 
No entender do entrevistado $\mathrm{n}^{\circ} 7$, no que tange ao sentido do ensino médio, considera que atualmente houve uma inversão de valores na qual a educação deixa de centrar-se no processo de formação humana para importar-se com a certificação para o mercado de trabalho. Nesse sentido, o currículo escolar, como prática formativa, modifica sobremaneira as relações humanas com o conhecimento. O conhecimento é estratificado em disciplinas pautadas em conteúdo escolar. Dessa maneira, como reporta o entrevistado a formação escolar está reduzida a parâmetros de eficiência e eficácia ligados ao desenvolvimento de competências e habilidades para que o aluno seja considerado, ao final do processo avaliativo, como apto a progredir na sua formação para a empregabilidade numa perspectiva de formação que venha atender à ótica do capital humano.

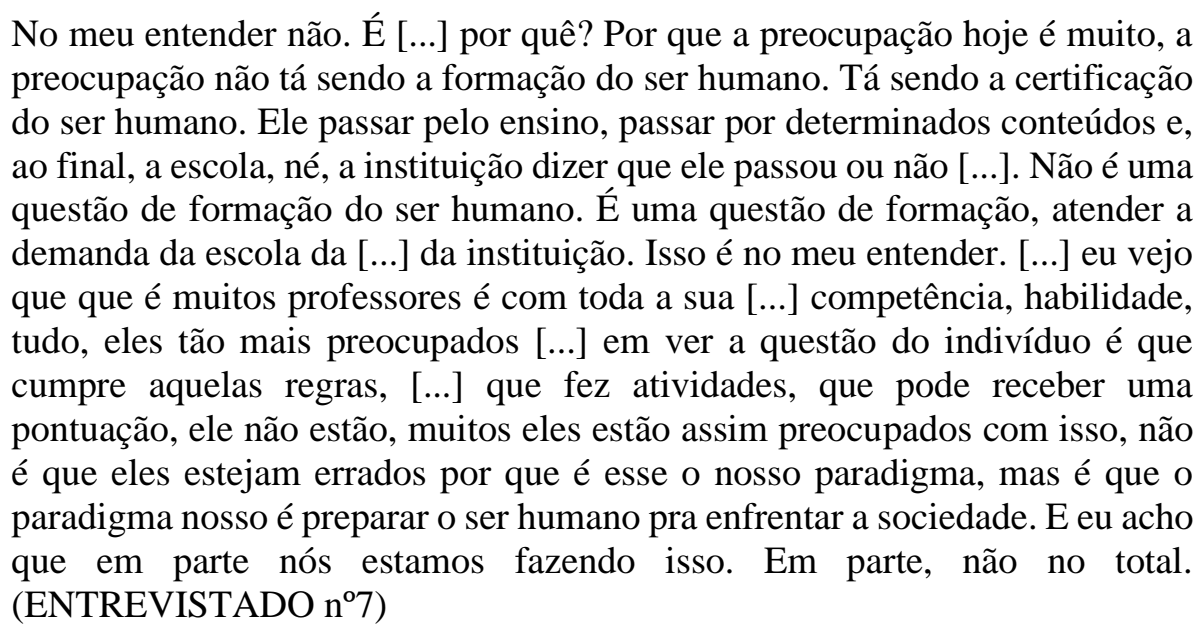

A partir dessas reflexões, coloca-se que a organização escolar está à disposição para atender à perspectiva de formação sob a égide do mercado de trabalho. Assim, a forma que as instituições educacionais lidam com o conhecimento estão restritas ao desenvolvimento de competências e habilidades. Nesse sentido, os processos educacionais - os conteúdos, metodologias e avaliação - são instrumentos de uma prática social que reproduz a práxis de organização empresarial com base na produção do saber para alcançar fins de desenvolvimento da força de produção pela ótica do capital. Assim, o termo "enfrentar a sociedade" tem sentido dúbio, pois, pode-se compreender a formação escolar para conformação das estruturas postas na sociedade para que o "sujeito qualificado" possa competir no mercado de trabalho por uma vaga de emprego, ou o termo pode-se referir a uma perspectiva formativa que visa à transformação das estruturas vigentes.

\section{Considerações finais}

A história da educação mostra que mesmo com tantas reformas no sistema de ensino, o ensino médio continua sendo um dos gargalos da educação básica no país. Cabe questionarmos 
que cidadãos pretendemos formar e quais interesses predominam nesse movimento dialético e contraditório em meio ao capitalismo. No caso brasileiro, marcado pela dependência do capital estrangeiro e pela ótica de mercado que enxergam o trabalhador como um capital produtivo de adestramento da força de trabalho em detrimento da formação omnilateral do sujeito. Dessa maneira, esse entendimento compreende que o significado do trabalho no capitalismo é separado da compreensão do trabalho enquanto princípio educativo.

Assim, no contexto do ensino médio integrado, o movimento da formação propedêutica e formação profissional é compreendido como um todo articulado e indissociável que se retroalimenta. Ou melhor dizendo, a formação propedêutica não é só teórica, pois parte da realidade, e a formação profissional necessita da fundamentação teórica para embasar a prática. Assim, a integração revela-se como um processo de aprofundamento do conhecimento contextualizado e problematizado na realidade. Para isso, é necessário compreender os fundamentos que abarcam esse fenômeno para construção dos espaços de debates e diálogos convergindo com a concepção de formação do ensino médio integrado.

A formação do ensino médio integrado à formação profissional, em alguns discursos, não está atrelada à formação inteira do sujeito, pensada pelo viés da politecnia, visando superar o dualismo educacional. Nessa ótica, quando abordamos sobre a formação profissional integrada à formação do ensino médio perpetua a lógica de formação para o mercado de trabalho como se o compromisso do ensino médio integrado fosse estritamente à formação profissional técnica.

Nesse movimento dialético de compreender o conhecimento, temos que levar em consideração a indissociabilidade da teoria e da prática, da formação propedêutica e da formação profissional, tendo a teoria como fundamento da prática e a prática como ação de transformação da realidade. Assim, quando falamos de ensino médio integrado temos que ter clareza epistemológica de que pedagogia formativa estamos nos referindo, de modo a considerar que a formação educacional integrada compreende a articulação entre a educação, o trabalho, a cultura, a ciência e a tecnologia como dimensões da vida do trabalhador.

Por fim, o estudo demostra também que existe discordância sobre que sujeito está se formando no ensino médio integrado. Alguns discursos enunciam que a formação profissional integrada ao ensino médio deveria formar técnicos para atuar na área de formação de forma imediata. Entretanto, outros sujeitos acreditam que a formação profissional integrada ao ensino médio possibilita o aluno fazer escolhas no que diz respeito ao processo formativo. E é isso, a formação de ensino médio integrado à formação profissional possibilita, a partir de uma 
perspectiva da totalidade da realidade, o aluno fazer escolhas da formação no sentido omnilateral do termo.

\section{REFERÊNCIAS}

ARAUJO, Ronaldo Marcos de Lima; FRIGOTTO, Gaudêncio. Práticas pedagógicas e ensino integrado. Revista Educação em Questão, v. 52, n. 38, p. 61-80, 2015. Disponível em: https://periodicos.ufrn.br/educacaoemquestao/article/viewFile/7956/5723. Acesso em 27 de fevereiro de 2018.

ARAÚJO, R. M. L.; RODRIGUES, D. S. Referências sobre práticas formativas em Educação Profissional: o velho travestido de novo ante o efetivamente novo. Boletim Técnico do Senac, Rio de Janeiro, v.36, n.2, maio/ago. 2010. Disponível em: http://www.senac.br/bts/362/artigo4.pdf. Acesso em 27 de fevereiro de 2018.

BRASIL. Diretrizes Curriculares Nacionais para a Educação Profissional Técnica de Nível Médio. In: Diretrizes e Curriculares Nacionais para o Ensino Médio. Brasília: MEC, SEB, DICEI, 2013.p. 202-265.

CIAVATTA, M. A formação integrada: a escola e o trabalho como lugares de memória e de identidade. Trabalho Necessário, v.3, n.3, 2005. Disponível em: http://www.uff.br/trabalhonecessario/images/TN_03/TN3_CIAVATTA.pdf. Acesso em 05 de março de 2018.

FRIGOTTO, Gaudêncio; CIAVATTA, Maria; RAMOS, Marise (Orgs.). Ensino médio integrado: concepções e contradições. - 2. Ed. - São Paulo: Cortez, 2010.

FRIGOTTO, Gaudêncio; CIAVATTA, Maria; RAMOS, Marise (Orgs.). Ensino médio integrado: concepções e contradições. - 3. Ed. - São Paulo: Cortez, 2012.

FRIGOTTO, Gaudêncio. Contexto e sentido ontológico, epistemológico e político da inversão da relação educação e trabalho para trabalho e educação. Revista Contemporânea de Educação, vol.10, n.20, jul./dez. de 2015. p.228-248. Disponível em: https://revistas.ufrj.br/index.php/rce/article/view/2729. Acesso: 07 de setembro de 2020.

KUENZER, A.Z; GRABOWSK, G. A produção do conhecimento no campo da educação profissional no regime de acumulação flexível. HOLOS, ano 32, v.6, p.22-32, agos-set, 2016. Disponível em: http://www2.ifrn.edu.br/ojs/index.php/HOLOS/article/view/4983. Acesso: 05 de setembro de 2020.

MACHADO, Lucília. Ensino médio e técnico com currículos: proposta de ação didática para uma relação não fantasiosa. In: ensino médio integrado à educação profissional. Ministério da Educação. Programa Salto para o Futuro. Ensino Médio Integrado à Educação Profissional. Boletim 07. Maio/Junho, 2006.

MACHADO, Lucília R. de Souza. Politecnia no ensino de segundo grau. In.: Politecnia no ensino médio. São Paulo: Cortez; Brasília: SENEB, 1991, p. 51-64. 
MARQUES, Welisson. Metodologia de pesquisa em análise do discurso face aos novos suportes midiáticos. Revista Eletrônica de Linguística: domínio da linguagem. Volume 5, $\mathrm{n}^{\circ} 1-1^{\circ}$ Semestre 2011 - ISSN 1980-5799. Disponível em:

http://www.seer.ufu.br/index.php/dominiosdelinguagem/article/view/12277/8054. Acesso em 07 de julho de 2019.

MOURA, Dante Henrique. Educação básica e educação profissional e tecnológica: dualidade histórica e perspectiva de integração. Holos, Natal, v.2, p.1-27, 2007. Disponível em: http://www2.ifrn.edu.br/ojs/index.php/HOLOS/article/viewFile/11/110. Acesso em $08 \mathrm{de}$ abril de 2018.

NOSELLA, Paolo. Trabalho e perspectivas de formação dos trabalhadores: para além da formação politécnica. Revista Brasileira de Educação, v.12, n.34 jan./abr. 2007. Disponível: http://www.scielo.br/pdf/rbedu/v12n34/a11v1234.pdf. Acesso em 03 de fevereiro de 2018.

RAMOS, M. N. Concepção do ensino médio integrado. Texto apresentado em seminário promovido pela Secretaria de Educação do Pará nos dias 8 e 9 de maio de 2008. Disponível em: http://www.iiep.org.br/curriculo_integrado.pdf. Acesso em 02 de fevereiro de 2018.

SIMÕES, Carlos Artexes. Educação técnica e escolarização de jovens trabalhadores. In: MOLL, Jaqueline. Educação Profissional e Tecnológica no Brasil Contemporâneo: desafios, tensões e possibilidades. Porto Alegre: Artmed, 2010.

\section{SOBRE OS AUTORES:}

\section{Ronivaldo Ferreira Mendes}

Mestre em Educação pelo IFTM - Campus Uberaba. Pedagogo no IFNMG - Campus Almenara - Brasil; Vinculado ao Grupo de Pesquisa em Discurso e Educação (GPDE/FTM/CNPq); Bolsista pelo Programa Institucional de Bolsas para Qualificação de Servidores - PBQS IFNMG. Correio eletrônico: ronivaldoferreiramendes@gmail.com

https://orcid.org/0000-0003-3227-7461

\section{Welisson Marques}

Doutor em Estudos Linguísticos - UFU. Professor e Coordenador do Programa de PósGraduação em Educação - Mestrado Profissional em Educação Tecnológica no IFTM Campus Uberaba - Brasil; Líder do Grupo de Pesquisa em Discurso e Educação (GPDE/FTM/CNPq).Correio eletrônico: welissonmarques@iftm.edu.br

(iD) https://orcid.org/0000-0001-6766-4651 